\title{
Papers
}

\section{Search for retrovirus in the chronic fatigue syndrome}

JW Gow, K Simpson, A Schliephake, W M H Behan, L J A Morrison, H Cavanagh, A Rethwilm, P O Behan

\begin{abstract}
Aim: To examine peripheral blood and skeletal muscle from patients with chronic fatigue syndrome for exogenous retrovirus.

Methods: Blood samples from 30 patients and muscle biopsy specimens of 15 patients were examined for retroviral sequences by DNA extraction, polymerase chain reaction (PCR), and Southern blotting hybridisation. Sera were examined for human foamy virus by western immunoblotting and indirect immunofluorescence techniques.

Results: No difference between the patient and control populations was found for any of the PCR primer sets used (gag, pol, env, and tax regions of HTLV IIII). An endogenous gag band was observed in both the patient and control groups. All sera were negative for antibody to human foamy virus.

Conclusion: The results indicate that there is no evidence of retroviral involvement in the chronic fatigue syndrome.
\end{abstract}

(F Clin Pathol 1992;45:1058-1061)

The postviral fatigue syndrome, also known as the chronic fatigue and immune dysfunction syndrome (CFIDS), is a disorder of unknown aetiology, characterised by severe fatigue together with myalgia. ${ }^{2}$ Its investigation has been difficult because of the lack of objective clinical laboratory findings, but strict diagnostic criteria have now been established so that appropriate studies can be made. ${ }^{34}$ The disease occurs in epidemics, where it has been reported under a variety of names such as neuromyasthenia and benign encephalomyelitis, ${ }^{2}$ but it is also endemic and single cases now present much more commonly. ${ }^{5}$ No one virus was ever isolated from the epidemic cases. Because of the clinical similarity with the chronic mononucleosis syndrome, EpsteinBarr virus had been considered a likely agent, but recent studies have ruled out this possibility, showing no correlation between the presence of chronic fatigue and increased antibody titres to the Epstein-Barr virus. ${ }^{6}$

The enteroviruses, especially Coxsackie viruses have often been thought to have a role. We looked for enteroviral genomes in the muscle biopsy specimens of a large number of well characterised patients with postviral fatigue syndrome and identified enteroviral specific nucleic acid sequences in $53 \%$ of patients, compared with $15 \%$ of age and sex matched controls.

Numerousimmunologicalabnormalities have also been demonstrated in these patients, ${ }^{18}$ but whether these are primary immune defects, leading to the establishment of a chronic infection, or produced secondarily by a viral infection, has not been determined. None the less the deficiencies identified led a group at the Wistar Institute in Philadelphia to search for evidence of retroviral involvement in the disease. They reported that examination of peripheral blood samples provided positive evidence of a human $T$ lymphotropic-like virus in most of the patients and they postulated a causal relation.

We studied a group of well characterised patients with postviral fatigue syndrome from the West of Scotland, to determine if an exogenous retrovirus was present. We examined peripheral blood mononuclear cells and muscle biopsy specimens at the nucleic acid level using gene amplification in each of the four regions of the retroviral genome by means of the polymerase chain reaction (PCR), followed by Southern blot hybridisation. Because of the very recent suggestion (by Professor W John Martin, personal communication, National Chronic Fatigue Syndrome Advisory Council, CDC, Atlanta, September 1991) that another retrovirus, the human foamy virus, might be associated with postviral fatigue syndrome, we also looked for specific antibodies to this virus in the serum of patients and controls, using western immunoblotting and indirect immunofluorescence techniques.

\section{Methods}

Thirty patients who fulfilled the criteria established for postviral fatigue syndrome and CFIDS were studied. ${ }^{4}$ They all complained of severe fatigue, which was made worse by exercise and had been present for more than a year. They were admitted as inpatients so as to exclude all the other conditions which enter into the differential diagnosis of the syndrome. None had received blood transfusions.

The control group consisted of 30 age and sex matched subjects, of whom 15 were healthy volunteers and 15 had other neurological or muscular disorders, (migraine $(n=5)$, epilepsy $(n=2)$, rheumatoid arthritis $(n=3)$ and systemic lupus erythematosus $(n=5))$.

Peripheral blood and muscle biopsy samples were coded by a person not involved in the experiments. Blood $(20 \mathrm{ml})$ was taken from 
patients and controls and peripheral blood mononuclear cells (PBMC) were isolated. The serum was stored at $-70^{\circ} \mathrm{C}$ until required. Muscle biopsy samples were taken from the right vastus lateralis of all patients with postviral fatigue syndrome and the 15 patients with other neuromuscular disorders, using the $\mathrm{UCH}$ biopsy needle to obtain two cores of skeletal muscle. These were snap frozen in liquid nitrogen and stored till use.

To reduce the risk of laboratory contamination, amplification of coded samples was carried out under strict containment procedures. High molecular weight DNA was prepared from PBMC and skeletal muscle, as described. $^{10}$ The preservation of the DNA was assured by amplifying a $1 \mu \mathrm{g}$ aliquot with a control cellular gene, endogenous tyrosine kinase, using $\mathrm{ABL}$ gene primers. ${ }^{7}$ Only those samples that gave a positive ABL gene band were used for analysis with retroviral primers.

The primers used for PCR amplification and the probes used to detect amplified sequences were selected from four regions, gag, tax, pol and $e n v$ of the retroviral genome.

(1) Two sets of gag primers for HTLV-II were used, the first as described in the previous positive study ${ }^{9}$ and consisting of nucleotides 807-40 and 1214-87. The probe, also as described, ${ }^{9}$ spanned nucleotides 1080-1105. Plasmid PMT2 (encoding HTLV-I sequence) was also used as a probe for this primer set and for the second primer set which was synthesised in our laboratory and consisted of nucleotides 1374-98 and 1573-97.

(2) The two pol primers SK110 and SK111 were obtained from Cetus. ${ }^{11}$ They amplify sequences common to the pol regions of HTLV-I and II. Two specific internal probes SK112 and SK118 (Cetus) were used. ${ }^{11}$

(3) The two env primers consisted of nucleotides 5689-5713 and 6002-6026, synthesised in our laboratory. These amplify sequences in HTLV-II.

(4) The two tax primers SK43 and SK44 were obtained from Cetus. " They would be expected to amplify sequences from the tax regions of both HTLV-I and II. No probe was used because the PCR results were negative.

PCR Amplification and hybridisation results in 30 patients with postviral fatigue syndrome and 30 control subjects

\begin{tabular}{|c|c|c|c|c|c|}
\hline \multirow[b]{2}{*}{ Primers } & \multicolumn{2}{|l|}{$P C R$ result } & \multirow[b]{2}{*}{ Probe } & \multicolumn{2}{|c|}{ Probe result } \\
\hline & Patients & Controls & & Patients & Controls \\
\hline $\begin{array}{r}\text { HTLV-II gag } \\
\text { bp 1374-98 } \\
1573-97\end{array}$ & Positive & Positive & pMT2 & Negative & Negative \\
\hline $\begin{array}{l}\text { HTLV-II gag } \\
\text { bp } 807-40 \\
1214-87(9)\end{array}$ & Positive & Positive & $\begin{array}{l}\text { pMT2 } \\
\text { bp } 1080-1105(9)\end{array}$ & $\begin{array}{l}\text { Negative } \\
\text { Negative }\end{array}$ & $\begin{array}{l}\text { Negative } \\
\text { Negative }\end{array}$ \\
\hline $\begin{array}{l}\text { HTLV I/II pol } \\
\text { SK110/111 }\end{array}$ & Positive & Positive & $\begin{array}{l}\text { SK112 } \\
\text { SK118 }\end{array}$ & $\begin{array}{l}\text { Negative } \\
\text { Negative }\end{array}$ & $\begin{array}{l}\text { Negative } \\
\text { Negative }\end{array}$ \\
\hline $\begin{array}{l}\text { HTLV II } e n v \\
\text { bp } 5689-5713 \\
6002-6026\end{array}$ & Negative & Negative & None & ND & ND \\
\hline $\begin{array}{l}\text { HTLV-I/II tax } \\
\text { SK } 43 / 44\end{array}$ & Negative & Negative & None & ND & ND \\
\hline
\end{tabular}

Positive control: pMT2 (HTLV-I)DNA was positive for both sets of gag PCR primers and positive in subsequent hybridisation with pMT2 and the base pair 1080-1105 gag probe. nd $=$ not done.
The cell line C8166 was used as a positive control. It is an HTLV-I transformed cell line and does not release infectious virions. ${ }^{12}$ Titration experiments using this control and an uninfected cell line confirmed that one infected target cell in about 100000 infected cells could be detected. Repeat experiments were performed with a variety of Taq polymerase enzymes and buffers from Promega (Southampton, England), du Pont (Hertfordshire, England) and Perkin-Elmer Centre (Buckinghamshire, England), to ensure that low copy numbers of virus would not be missed.

DNA amplification was performed with a programmable Techne Cambridge heating block set to give 35 cycles of one minute at $94^{\circ} \mathrm{C}$, one minute at $55^{\circ} \mathrm{C}$, and 1.2 minutes at $72^{\circ} \mathrm{C}$ for all primer sets. The products were electrophoresed through $2 \%$ agarose gels, stained with ethidium bromide, and visualised under ultraviolet light. Gels were then immobilised on a nylon membrane (GeneScreen Plus) and hybridised with the appropriate ${ }^{32} \mathrm{P}$-labelled internal probe. Filters were washed at low stringency to retain any mismatched hybrids. Blots were exposed for up to 21 days to Kodak XAR5 film with intensifying screens at $-70^{\circ} \mathrm{C}$.

Serum antibodies to another retrovirus, from the spumavirus family, the human foamy virus were sought by western immunoblotting.

Western blot antigen was prepared by concentrating human foamy virus (HFV) from the supernatant fluid of lytically infected baby hamster kidney cells (BHK-21), by the method of Netzer et al, ${ }^{13}$ in the Institut für Virologie and Immunbiologie in Würzburg. Serum dilutions of 1 in 25 were used, although positive sera will produce a reaction at 1 in 100 . The positive pattern on the western blot is similar to that described for radioimmunoprecipitation assay. ${ }^{13}$

The indirect immunofluorescence assay was also carried out at the Institut für Virologie and Immunbiologie, Würzburg. Baby hamster kidney cells (BHK-21) infected with human foamy virus were used as a substrate. The serum samples were tested in an indirect immunofluorescence assay, as described. ${ }^{1.4}$ Sera positive for antibodies to human foamy virus will produce brilliant nuclear staining of the infected cells.

\section{Results}

The results of the PCR experiments are shown in the table.

The two sets of HTLV-II gag primers gave rise to a specific band in all patient and control samples. The published gag primers nucleotides 807-1287,' gave rise to a band of 440 base pairs in length. When the products were hybridised to the probe, the retroviral plasmid pMT2, however, no specific signal was detected. Hybridisation of gag primer product 807-1287 with the $85 \%$ GC-rich internal gag probe was also negative. No other PCR product was detectable. The PCR product band should have been 409 base pairs in length for a 
sequence of HTLV-II, and we postulate, therefore, that the 440 base pair band obtained must represent endogenous retrovirus.

The pol region primers also produced specific bands in all patients and controls: a product of about 186 base pairs was obtained in each case, but hybridisation with the HTLVI and HTLV-II specific probes was negative.

The env and tax region primer experiments were negative in both groups.

Examination of the sera of the patient and control groups revealed no antibodies to human foamy virus by western blotting or immunofluorescence assay.

These results provide no evidence that exogenous retroviral sequences are present in peripheral blood cells or muscle of patients with postviral fatigue syndrome, nor do the patients have antibodies to another member of the retrovirus family, the human foamy virus.

\section{Discussion}

Our results provide no evidence of retroviral involvement in the chronic fatigue syndrome. We found no sequences indicative of the exogenous retroviruses HTLV-I or II in the peripheral blood or muscle biopsy specimens of the patients and no specific antibodies in their serum to a spumavirus, the human foamy virus.

Retroviral involvement in postviral fatigue syndrome was originally considered because this is an unusual chronic neurological disease with immune abnormalities and, as such, bears some similarity to tropical spastic paraperesis, a disorder in which HTLV-I has been shown to be the aetiological agent. ${ }^{15}$

Our patient group was strictly defined. ${ }^{34}$ They each had a typical history with severe fatigue present for at least one year. All were admitted to hospital in order to exclude any other causes for their symptoms. As regards methodology, we used universal sets of primers which should amplify the published positive PCR product and other PCR products common to human retroviruses. This strategy should have increased the chances of detecting a new, related retrovirus. The specificity and sensitivity of the oligonucleotides were confirmed using a cell line infected with HTLV-I and showing that one infected cell in 100000 could be detected. The probes used were positive in the positive control hybridisation.

Other workers have recently reported that retroviral sequences can be detected in a proportion of patients with postviral fatigue syndrome. ${ }^{9}$ Their patient group was characterised by the same criteria as ours, but was from North Carolina and New York. PCR amplification of gene sequences was also used by this group, for gag and tax regions of HTLVI and II. They found that the HTLV-II gag primers were positive in 20 of 28 patients, with seven of 10 of these cases showing confirmation of positivity by specific probes in an in situ hybridisation study of peripheral blood mononuclear cells. Sixty one per cent of the cases had antibodies to HTLV viral antigens.
We used the same primers as the above workers but our results are different. The most important finding we made was that the gag primers used amplified a sequence in both patients and controls, which thus probably represents an endogenous retroviral sequence. The disparity between our results can be explained because de Freitas et $a l^{9}$ used two control groups, one of them being an "exposure" group of individuals, in contact with an epidemic of postviral fatigue syndrome, or with affective individuals, but unaffected themselves. In this group there were indeed $30 \%$ of samples positive to the gag PCR test and $43 \%$ of samples positive to the HTLV western blot. Thus, positive results were detectable in patient and control groups, as in our study. Our interpretation is that the sequence is endogenous, rather than exogenous, virus.

PCR methodology has to be used with caution because of its inherent weakness-its false positive results. ${ }^{1617}$ The strictest contaminant facilities must be used and it has to be recognised that sporadic, unreproducible signals may be generated in a few samples examined. Repetition, stringent analysis, and use of specific probes are necessary to exclude (or confirm) results. ${ }^{17}$

The situation in postviral fatigue syndrome bears some analogy with that for multiple sclerosis, where again diagnosis may be difficult and clinical course unpredictable. Koprowski and colleagues, ${ }^{18}$ among others, originally reported retroviral involvement in this disease too. Their work was followed by at least 10 carefully controlled studies, carried out worldwide, and culminating in a huge, blind examination of 1000 samples from patients, each of which concluded that there was no evidence of such a retroviral association, when false positive results, including endogenous retroviral sequences, had been excluded. ${ }^{19}$

The involvement of other viruses in postviral fatigue syndrome, however, is undoubtedly a strong possibility. We have recently reported that enteroviral genome can be detected in the muscle of $53 \%$ of these cases, compared with $15 \%$ of control subjects. ${ }^{7}$ Enteroviral sequences may be present in peripheral blood mononuclear cells, but equally prevalent in patients and controls, suggesting that infection of these cells is related purely to the numbers of enteroviruses circulating in the community at the time. The high incidence in the muscle of patients, however, which is not related to peripheral blood findings, suggests that there is a low grade, chronic enteroviral infection of the tissue. Oldstone and his colleagues ${ }^{20}$ have shown that such persistent viral infections are associated with interference in cell metabolism. Structural abnormalities in muscle mitochondria has been identified in some cases of postviral fatigue syndrome, ${ }^{21}$ suggesting that the characteristic fatigue may be related to the effect of chronic enteroviral or other viral infection on these organelles.

From the data reported here, we cannot exclude the possibility that a very distantly related retrovirus is also associated with post- 
viral fatigue syndrome, but this seems very unlikely.

This work was supported by a generous grant from the Barclay Trust of Glasgow University and by the Deutsche Forschungsgemeinschaft. We are grateful to Dr R Jarrett, Department of Veterinary Pathology, Glasgow University, for providing the pMT2 clone and the cell line C8166. We thank Dr $\mathrm{R}$ Madhok for some of the control blood samples and Jean Rodgers BSc for technical assistance.

1 Behan PO, Behan WMH. The postviral fatigue syndrome. Crit Rev Biol 1988;4:157-78.

2 Henderson DA, Shelokov A. Epidemic neuromyasthenia: clinical syndrome? N Engl f Med 1959;260:757.

3 Holmes GP, Kaplan JE, Gantz NM, et al. Chronic fatigue syndrome: a working case definition. Ann Intern Med 1988;108:387-9.

4 Behan PO, Bakheit AMO. Clinical spectrum of postviral fatigue syndrome. Br Med Bull 1991;47:793-808.

5 Ramsay AM. Epidemic neuromyasthenia 1955-1978. Postgrad Med f 1978;54:718-9.

6 Straus SE. History of chronic fatigue syndrome. Rev Infect Dis 1991;13:S1-S7.

7 Gow J, Behan WMH, Clements GB, et al. Enteroviral sequences detected by PCR in muscle biopsies of patients
with the postviral fatigue syndrome. BMF 1991; with the

8 Morrison LJA, Behan WMH, Behan PO. Changes in natural killer cell phenotype in patients with postviral fatigue syndrome. Clin Exp Immunol 1991;83:441-6.

9 de Freitas E, Hilliard B, Cheney PR, et al. Retroviral sequences related to human T-lymphotropic virus type II in patients with chronic fatigue immune dysfunction syndrome. Proc Natl Acad Sci USA 1991;88:2922-6.
10 Sambrook J, Fritsch E, Maniatis T, eds. Molecular cloning, a laboratory manual. 2nd Edn. Cold Spring Harbor, New York, Cold Spring Harbor Laboratory. 1989.

11 Kwok S, Kellogg D, Ehrlich G, et al. Characterization of a sequence of human $\mathrm{T}$ cell leukaemia virus Type I from a patient with chronic progressive myelopathy. $\mathcal{F}$ Infect Dis 1988;158:1193-7.

12 Salahuddin SZ, Markham PD, Wong-Staal, et al. Restricted expression of human T-cell leukaemia- lymphoma virus lymphocytes. Virology 1983;129:51-64.

13 Netzer KO, Rethwilm A, Maurer B, et al. Identification of the major immunogenic structural proteins of human the major immunogenic structural prote

14 Neumann-Heafelin D, Rethwilm A, Bauer G, et al. Characterisation of a Foamy Virus isolated from cercopithecus terisation of a Foamy Virus isolated from cercopithecus aethiops lymphob

15 Osame M, Usuku K, Izumo S. HTLV-I associated myelopathy, a new clinical entity. Lancet 1986;i:1031-2.

16 Abbott M, Byrne B, Kwok S, et al. Enzymatic gene amplification: qualitative and quantitative methods for detecting proviral DNA amplified in vitro. $f$ Infect Dis 1988;158:1158-69.

17 Kwok S, Higuchi R. Avoiding false positives with PCR. Nature 1989;339:237-8.

18 Koprowski $\mathrm{H}$, de Freitas EC, Harper ME, et al. Multiple sclerosis and human T-cell lymphotropic retroviruses. Nature 1985;318:154-60.

19 Ehrlich GD, Glaser JB, Bryz-Gornia MS, et al. Multiple sclerosis, retroviruses and PCR. Neurology 1991; 41:335-43.

20 Southern P, Oldstone MBA. Medical consequences of persistent viral infection. $N$ Engl f Med 1986;314:359.

21 Behan WMH, More IAR, Behan PO. Mitochondrial abnormalities in the postviral fatigue syndrome. Acta Neuropathol 1991;83:61-5. 